\title{
Preventive effects of polyphenol-rich perilla leaves on oxidative stress and haemolysis
}

\author{
Wachiraporn Tipsuwan, Wittaya Chaiwangyen* \\ Division of Biochemistry and Nutrition, School of Medical Sciences, University of Phayao, \\ Phayao 56000 Thailand \\ *Corresponding author, e-mail: wittaya.ch@up.ac.th
}

Received 11 May 2018

Accepted 12 Jun 2018

\begin{abstract}
We investigated the effect of perilla leaf extract (PLE) containing polyphenols on various biological functions including antioxidant activity, iron chelation, and red blood cell haemolysis protection. The total phenolic and flavonoid content were determined by colorimetric assay and HPLC analysis. The antioxidant activity was determined by DPPH and ABTS assay. The iron chelating effect was examined by the colorimetric method. Free radical scavenging activity was determined by haemoglobin-induced lipid peroxidation in a linoleic acid model system. Reactive oxygen species (ROS) inhibition was investigated in peripheral blood mononuclear cells. The antihaemolytic activity by AAPHinduced free radicals. The results revealed that PLE contained high levels of total phenolic compounds and total flavonoids (mainly rosmarinic acid). The $\mathrm{IC}_{50}$ values of PLE by DPPH and ABTS radical scavenging assay were $34.3 \pm 3.4$ and $9.69 \pm 0.14 \mu \mathrm{g} / \mathrm{ml}$, respectively. The iron-binding effect of PLE was exhibited by complex formation with $\mathrm{Fe}^{3+}{ }_{-} \mathrm{NTA}$. The iron-chelating activity displayed a moderate $\mathrm{IC}_{50}$ value of $10.1 \pm 0.6 \mathrm{mg} / \mathrm{ml}$. The PLE concentration of $200 \mu \mathrm{g} / \mathrm{ml}$, significantly inhibited intracellular ROS 45\%. The scavenging activity of PLE in haemoglobin-induced lipid peroxidation resulted in $27 \%$ inhibition. PLE also prevented AAPH-induced RBC haemolysis. In conclusion, PLE containing phenolic compounds plays a vital role in free radical scavenging and iron-chelating activities and subsequently prevents lipid peroxidation resulting from RBC haemolysis due to oxidative stress. Perilla products may be developed as health supplements, which could probably be used in prophylaxis and treatment of non-communicable diseases.
\end{abstract}

KEYWORDS: 'nga mon', chelation, free radical, rosmarinic acid

\section{INTRODUCTION}

It has been recognized that numerous non-communicable diseases (NCDs) such as cancer, diabetes, obesity, hypertension, and cardiovascular disease, are evidently associated with oxidative stress, which leads to cellular damage ${ }^{1}$. To prevent the corresponding result, the reduction of reactive oxygen species (ROS), induced oxidative reactions by antioxidants is a primary requirement ${ }^{2}$. Natural antioxidants such as polyphenols, bioflavonoids, rosmarinic acid, and luteolin have been found in a variety of local medicinal herbs and plant products $^{3,4}$. Perilla (Perilla frutescens or 'nga mon' in Thai), a medicinal herb in the mint family, is commonly cultivated in the hilly areas of northern Thailand. There are several varieties of perilla in Asian countries including $P$. frutescens var. crispa, $P$. frutescens var. frutescens, $P$. frutescens var. acuta, $P$. frutescens var. purpurascens, and $P$. frutescens var. auriculato-dentata ${ }^{5,6}$. Both the seeds and leaves of perilla have been traditionally used and consumed by the Asians due to their high contents of polyunsaturated fatty acids and several benefits including anti-inflammatory, antiallergic, and antioxidant properties $^{7,8}$. Recent studies have demonstrated that perilla leaves contain various antioxidant compounds, phenolics (coumaroyl tartaric acid, caffeic acid, and rosmarinic acid), and flavonoids (apigenin and luteolin) ${ }^{9,10}$. Previous studies reported that rosmarinic acid was a major polyphenol in perilla leaves ${ }^{11,12}$ and potentially exhibited several biological functions including antioxidant, antiinflammatory, antiallergic, and $\alpha$-glucosidase inhibitory activities ${ }^{13,14}$. However, no extensive studies have been done to investigate the preventive effects of perilla on membrane oxidation and haemolysis. Hence the aim of this study is to establish whether perilla leaf extract containing polyphenols could exhibit various biological functions including antioxidant activity, an inhibitory effect on lipid peroxidation, ROS scavenging activity, iron chelation 
property, and red blood cell haemolysis protection.

\section{MATERIALS AND METHODS}

\section{PLE preparation}

Perilla plants were grown in a field located at the University of Phayao. The voucher specimen of plant material was prepared by Dr Lapatrada Mungmai and certified by Sanga Saphasri Research and Development Department, the Botanical Garden Organization, Ministry of Natural Resource and Environment, Chiang Mai, Thailand, under the herbarium code QBG-93756. The leaves were collected and oven-dried before extraction. One hundred grams of the dried perilla leaves were ground into fine pieces before soaking in 11 of $70 \%$ ethanol and were regularly shaken (300 rpm) for $18 \mathrm{~h}$ at room temperature ${ }^{12}$. The solution was later filtered through Whatman No. 1 paper filter. The solvent was evaporated using a vacuum rotary evaporator (BUSHI, Switzerland) and the aqueous solution was then dried in a lyophilizer (Scanvac Coolsafe, Denmark). The perilla leaf extract (PLE) was stored at $-20^{\circ} \mathrm{C}$ until used.

\section{Phytochemical analysis of PLE}

Determination of total phenol contents: The colorimetric Folin-Ciocalteu assay was used to determine the total phenolic content (TPC) as adapted from Ref. 15. Gallic acid was used as a standard. Various concentrations of gallic acid were mixed with 10\% Folin-Ciocalteu reagent. The mixture was wellmixed before the addition of $7.5 \% \mathrm{Na}_{2} \mathrm{CO}_{3}$ and was allowed to stand at room temperature for $30 \mathrm{~min}$. The developed colour was measured at $765 \mathrm{~nm}$. The diluted PLE was also assayed with the same procedure. The TPC was expressed as milligrams of gallic acid equivalent (GAE) per gram extract. Each sample was analysed in triplicate.

Determination of flavonoid contents: The total flavonoid content in PLE was performed by colorimetric assay ${ }^{15}$. In brief, $250 \mu$ l of diluted PLE was mixed with $75 \mu \mathrm{l}$ of $5 \% \mathrm{NaNO}_{2}$ solution. The mixture was incubated at room temperature for $6 \mathrm{~min}$ before adding $150 \mu \mathrm{l}$ of $10 \% \mathrm{AlCl}_{3} \cdot 6 \mathrm{H}_{2} \mathrm{O}$ and further incubated at room temperature for $5 \mathrm{~min}$. The colour was developed by adding $500 \mu \mathrm{l}$ of $1 \mathrm{M}$ $\mathrm{NaOH}$ and the volume was adjusted to $2500 \mu \mathrm{l}$. The formation of the flavonoids-aluminium complex was measured at $510 \mathrm{~nm}$. The total flavonoid content was expressed as milligrams of catechin equivalent (CE) per gram extract. All samples were analysed in triplicate.

\section{HPLC chromatographic profile of TPC in PLE}

The HPLC chromatographic profile of TPC was analysed in PLE ${ }^{16}$. The PLE was prepared at $5 \mathrm{mg} / \mathrm{ml}$ in HPLC grade methanol. The phenolic standards consisting of rosmarinic acid, apigenin and luteolin (Chengdu Biopurify Phytochemicals Ltd., China). Samples were injected into the ODS-3-C18 column (4.6 $\mathrm{mm} \times 250 \mathrm{~mm}, 5 \mu \mathrm{m}$ particle diameters). The mobile phase system contained $0.1 \%$ trifluoroacetic acid (TFA) in water (a) and methanol (b). The flow rate was $1.0 \mathrm{ml} / \mathrm{min}$. A UV detector was used to detect the phenolic compounds at wavelengths of $280 \mathrm{~nm}$ and $320 \mathrm{~nm}$. The content of the phenolic compounds was quantified using calibration curves of standard phenolics and expressed as mg GAE/g extract.

Determination of the antioxidant capacity: $\mathrm{DPPH}$ radical scavenging activity was evaluated by colorimetric assay ${ }^{17}$. To prepare a radical, a 2,2-diphenyl1-picrylhydrazyl (DPPH) was dissolved in ethanol, then $20 \mu \mathrm{l}$ of diluted PLE in ethanol was mixed with $180 \mu \mathrm{l}$ DPPH radical. The incubation was carried out at room temperature for $15 \mathrm{~min}$ in the dark. The remaining DPPH radical was measured at $A_{540}$. Ascorbic acid and Trolox were used as standards. The antioxidant activity of PLE was expressed as $\mathrm{IC}_{50}$; a PLE concentration that would be able to scavenge DPPH radicals by $50 \%$. The concentration providing $50 \%$ inhibition $\left(\mathrm{IC}_{50}\right.$ ) was calculated from the graph plotting percentage of DPPH radical scavenging against the concentration of PLE.

ABTS radical scavenging activity was evaluated by colorimetric assay ${ }^{18}$. To prepare a radical, a $1: 1(\mathrm{v} / \mathrm{v})$ ratio of $7.5 \mathrm{mM}$ ABTS $\left(2,2^{\prime}\right.$-azinobis-(3ethylbenzothiazoline-6-sulphonic acid)) was mixed with $6.6 \mathrm{mM}$ potassium persulphate in water. The reaction mixture was allowed to stand in the dark for 12-16 h. Ten microlitres aliquot of each sample dilution was mixed with $990 \mu \mathrm{lBCS}^{\bullet+}$. The incubation was carried out in the dark at room temperature for $6 \mathrm{~min}$. The inhibition of $\mathrm{A}_{734}$ was measured. Ascorbic acid and Trolox were used as standards. The antioxidant activity of PLE was expressed as $\mathrm{IC}_{50}$; a PLE concentration that would be able to scavenge $\mathrm{ABTS}^{\bullet+}$ by $50 \%$. The concentration providing $50 \%$ inhibition $\left(\mathrm{IC}_{50}\right)$ was calculated from the graph plotting percentage of ABTS radical scavenging against the concentration of PLE.

A stock solution of PLE was freshly prepared by dissolving the extract powder in $50 \mathrm{mM}$ 3-[N-morpholino]propanesulphonic acid (MOPS) 
(Sigma-Aldrich Co., St. Louis, MO), pH 7.0 solution. A working $\mathrm{Fe}^{3+}$-NTA solution was freshly prepared by mixing stock $\mathrm{Fe}\left(\mathrm{NO}_{3}\right)_{3}$ solution (AAS iron reagent, $1000 \mathrm{ppm}$ in $0.5 \% \mathrm{HNO}_{3}$; APS Finechem, Seven Hills, Australia) with a nitrilotriacetate (NTA) solution (a molar ratio of $\mathrm{Fe}^{3+}: \mathrm{NTA}=1: 5$ ). Ironbinding activity was determined by the spectrophotometric technique. PLE $(1 \mathrm{mg} / \mathrm{ml})$ was incubated with $0-400 \mu \mathrm{M}$ of ferric nitrilotriacetate $\left(\mathrm{Fe}^{3+}\right.$. NTA), pH 7.0 at room temperature for $60 \mathrm{~min}$. The absorbance of the iron-PLE complexes was measured in the range of $200-800 \mathrm{~nm}$ by a scanning double-beam UV-Vis spectrophotometer Shimadzu, Japan $)^{19}$. PLE at $1 \mathrm{mg} / \mathrm{ml}$ was used as a blank.

Determination of iron-chelating activity: The chelating activity of perilla extract was performed by colorimetric assay ${ }^{20}$. In brief, perilla extract $(5-17.5 \mathrm{mg} / \mathrm{ml})$ was mixed well with $50 \mu \mathrm{l}$ of $2 \mathrm{mM}$ $\mathrm{FeCl}_{2}$ in $7.5 \% \mathrm{HCl}$. Then $200 \mu \mathrm{l}$ of $5 \mathrm{mM}$ ferrozine was added to react with free ferrous ions for $20 \mathrm{~min}$ at room temperature. The colour intensity of the ferrozine-iron complex was determined at $\mathrm{A}_{562}$. EDTA was used as a positive control. A blank sample was performed without ferrozine. To avoid the influence of colour intensity from the sample, the reactions containing the sample at various concentrations were performed in the absence of ferrozine. The colour intensity at $A_{562}$ of this sample set was deducted from the $A_{562}$ of the reaction in the presence of ferrozine. The concentration providing $50 \%$ inhibition $\left(\mathrm{IC}_{50}\right.$ ) was calculated from the graph plotting percentage of iron-chelating activity against the concentration.

Blood collection and RBC preparation: The blood sample collection was evaluated and approved by the Human Ethics committee of the University of Phayao (HE 57-02-04-0024). Heparinized human blood from healthy subjects was centrifuged at $1700 \mathrm{~g}$ for $10 \mathrm{~min}$. The packed RBCs obtained were washed 3 times with phosphate buffered saline (PBS), $\mathrm{pH} 7.4$ and in PBS and 5\% RBC suspension was prepared and used in the following tests.

Preparation of mononuclear cells: Peripheral blood mononuclear cells (PBMC) were separated from whole blood of normal human volunteers by using Ficoll-Hypaque reagent (HISTOPAQUE1077). Lymphocytes were cultured in suspension in RPMI 1640 medium supplemented with $10 \%$ heat-inactivated fetal bovine serum, penicillin $(100 \mathrm{U} / \mathrm{ml})$, and streptomycin $(100 \mathrm{U} / \mathrm{ml})$ at $37^{\circ} \mathrm{C}$. The cells were counted with the use of haemocytometer and cell viability was assessed by the trypan blue exclusion method ${ }^{21}$.

Determination of PLE on ROS inhibition in PBMC: The fluorochrome, $2^{\prime}-7^{\prime}$-dichlorofluorescein diacetate (DCFH-DA) was hydrolysed by an intracellular esterase to produce DCFH. Next, DCFH was oxidized by intracellular ROS to generate oxidized dichlorofluorescein (DCF). The cellular ROS productions were expressed as the fluorescence intensity of DCF ${ }^{22}$. To determine the effect of PLE on the cellular ROS inhibition, various concentrations of PLE $(0-200 \mu \mathrm{g} / \mathrm{ml})$ were incubated with PBMC for $2 \mathrm{~h}$. DCFH-DA was added to the cells and incubated at $37^{\circ} \mathrm{C}$ for $15 \mathrm{~min}$ in a humidified atmosphere of $5 \% \mathrm{CO}_{2}$ per $95 \%$ air. Then $\mathrm{FeSO}_{4}$ was added and incubation continued for $1 \mathrm{~h}$. The fluorescence intensity was determined by a fluorescence microplate reader at an excitation wavelength of $480 \mathrm{~nm}$ and an emission wavelength $525 \mathrm{~nm}$.

Determination of PLE on inhibition lipid peroxidation: To determine free radical scavenger activity of PLE, linoleic acid was used as lipid membrane model. Lipid peroxidation was induced by haemoglobin suspension. The lipid peroxidation was examined in triplicate by the thiocyanate method. This method was modified from Ref. 23. The reaction mixture contained PLE $(10-30 \mathrm{mg} / \mathrm{ml}), 40 \mu \mathrm{l}$ of linoleic emulsion $(1 \mathrm{mM}), 40 \mu \mathrm{l}$ of phosphate buffer (40 mM, pH 6.5) and haemoglobin suspension $(0.0016 \% \mathrm{v} / \mathrm{w})$ to a final volume of $200 \mu \mathrm{l}$. After incubation at $37^{\circ} \mathrm{C}$ for $45 \mathrm{~min}$, the lipid peroxidation reaction was terminated by adding $2.5 \mathrm{ml}$ of $0.6 \% \mathrm{HCl}$ in ethanol. Thereafter, $30 \mu \mathrm{l}$ of $\mathrm{FeCl}_{2}$ $(0.02 \mathrm{M})$ in $7.5 \% \mathrm{HCl}$ and $20 \mu \mathrm{l}$ of ammonium thiocyanate $(0.3 \mathrm{~g} / \mathrm{ml})$ were added for colouring the reaction. The absorbance was measured by a spectrophotometer at $480 \mathrm{~nm}$. Deionized water was used as a negative control and ascorbic acid as a positive control.

\section{Measurement of anti-haemolytic activity by PLE}

Lipid peroxidation in the RBC membrane was induced by $2,2^{\prime}$-azobis-2-methyl-propanimidamide dihydrochloride (AAPH) ${ }^{24}$. The RBC suspension was pre-incubated with various PLE concentrations (0$200 \mu \mathrm{g} / \mathrm{ml}$ ) at $37^{\circ} \mathrm{C}$ for $60 \mathrm{~min}$, washed twice with PBS and subjected to haemolysis. The tested red blood cells were incubated with $50 \mathrm{mM}$ AAPH for $3 \mathrm{~h}$ at $37^{\circ} \mathrm{C}$ with gentle shaking. Finally, the degree of haemolysis was evaluated by OD 540 by spectrophotometer. The reaction without the extract was used as a negative control. 
Table 1 Extraction yield and polyphenols content in PLE.

\begin{tabular}{lc}
\hline Compounds and contents in PLE & Values $(n=3)$ \\
\hline Extract yield (\% by weight) & $7.50 \pm 0.64$ \\
TPC (mg GAE/g extract) & $255.5 \pm 5.3$ \\
TFC (mg CE/g extract) & $296.7 \pm 4.7$ \\
Rosmarinic acid (mg/g extract) & $159.7 \pm 1.4$ \\
Apigenin (mg/g extract) & $0.49 \pm 0.08$ \\
Luteolin (mg/g extract) & $0.28 \pm 0.06$ \\
\hline
\end{tabular}

\section{Statistical analysis}

The statistical analysis was performed using oneway ANOVA, followed by Tukey's multiple comparisons test. The $p$ value of $<0.05$ was defined as significant. Data were expressed as mean \pm SD.

\section{RESULTS}

\section{The phytochemical analysis of PLE}

As indicated in Table 1, the yields of PLE was $7.50 \pm 0.64 \%$ by weight. The TPC and TFC were $255.5 \pm 5.3 \mathrm{mg} \mathrm{GAE} / \mathrm{g}$ extract and $296.7 \pm 4.7 \mathrm{mg}$ CE/g extract, respectively. The HPLC chromatogram revealed the major peak belonged to rosmarinic acid, at retention time $17.4 \mathrm{~min}$ (Fig. 1). Small contents of apigenin and luteolin were also detected in the extract.

\section{Determination of the antioxidant capacity}

The antioxidant activity of PLE was determined using DPPH and ABTS radical scavenging assay. As shown in Fig. 2a, PLE would be able to inhibit the DPPH radicals in a dose-dependent manner with an $\mathrm{IC}_{50}$ of $34.3 \pm 3.4 \mu \mathrm{g} / \mathrm{ml}$. Similarly, PLE could suppress the stable $\mathrm{ABTS}^{\bullet+}$ with an $\mathrm{IC}_{50}$ of $9.69 \pm 0.14 \mu \mathrm{g} / \mathrm{ml}$ (Fig. 2b). The result indicated the antioxidant property of PLE.

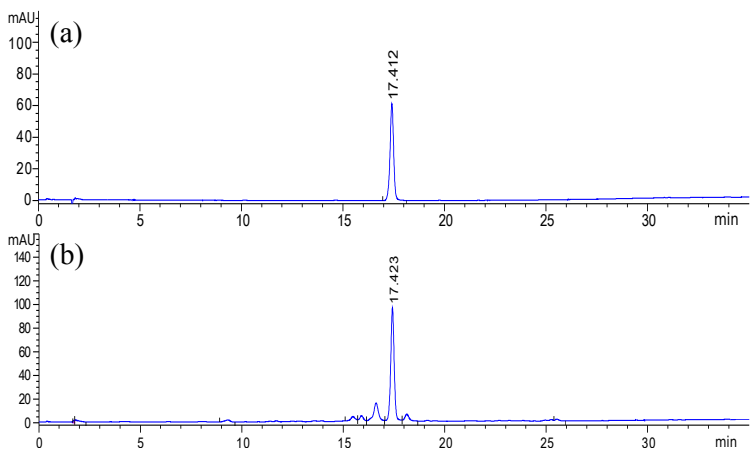

Fig. 1 HPLC chromatogram of (a) standard rosmarinic acid and (b) PLE.
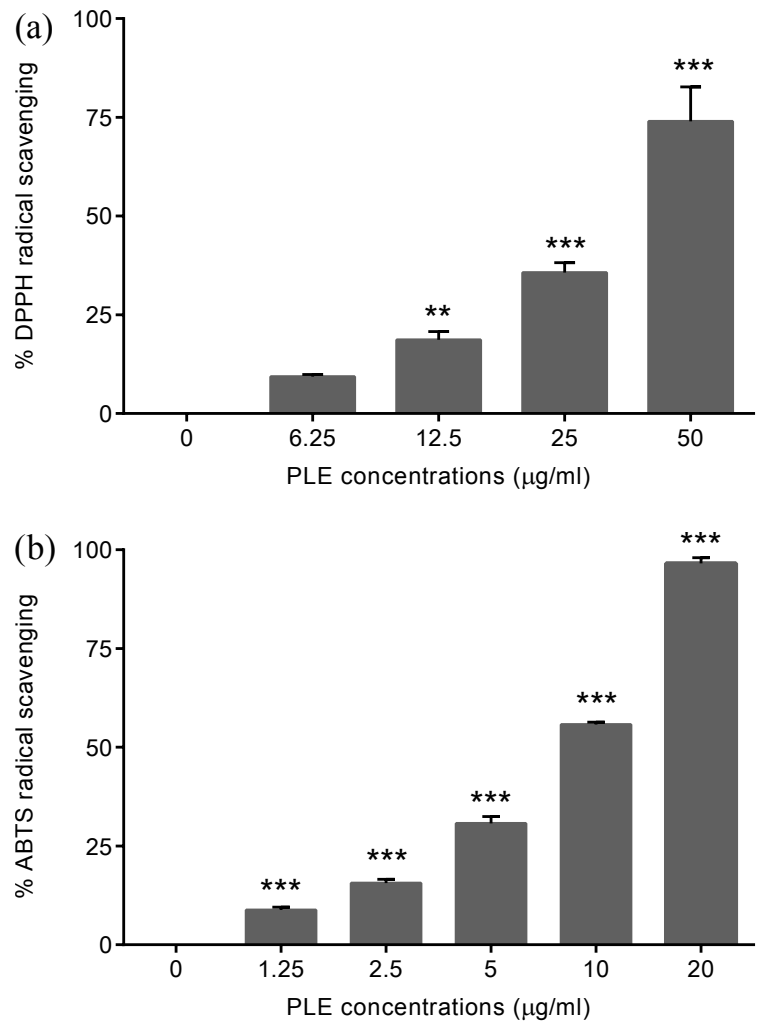

Fig. 2 Antioxidant activity of PLE by using (a) DPPH assay and (b) ABTS assay. All data are expressed as mean \pm SD $(n=3), * * p<0.01, * * * p<0.001$.

\section{Iron-binding activity of PLE}

The iron-binding activity of PLE was determined by scanning UV-Vis spectrophotometer in the range of 200-800 nm. The spectral analysis of the iron-PLE extract complexes exhibited the maximum absorption at 395 and $600 \mathrm{~nm}$, the respective major and minor peaks (Fig. 3). The absorbance of complexes was increased in a dose-dependent manner ( 0 $400 \mu \mathrm{M} \mathrm{Fe}^{3+}$-NTA).

\section{Iron-chelating activity of PLE}

The PLE was tested for the iron-chelating activity at various concentrations. As illustrated in Fig. 4, the red-purple colour intensity decreased in inverse relation to the increase of the PLE concentration. The iron-chelating activities of the PLE were comparable to the EDTA, as a positive control. The EDTA demonstrated very high chelating ability with an $\mathrm{IC}_{50}$ value of $0.031 \pm 0.001 \mathrm{mg} / \mathrm{ml}$ while the PLE could moderately chelate ferrous ions with an $\mathrm{IC}_{50}$ value of $10.1 \pm 0.6 \mathrm{mg} / \mathrm{ml}$. 


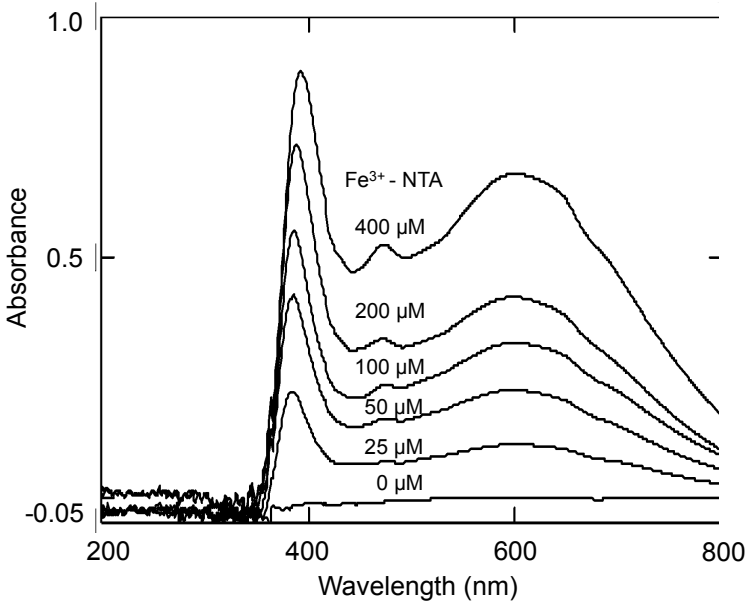

Fig. 3 Spectral analysis of the iron-PLE complex resulting from complexation of $\mathrm{Fe}^{3+}$-NTA $(0-400 \mu \mathrm{M})$ and PLE (1 $\mathrm{mg} / \mathrm{ml}$ ).
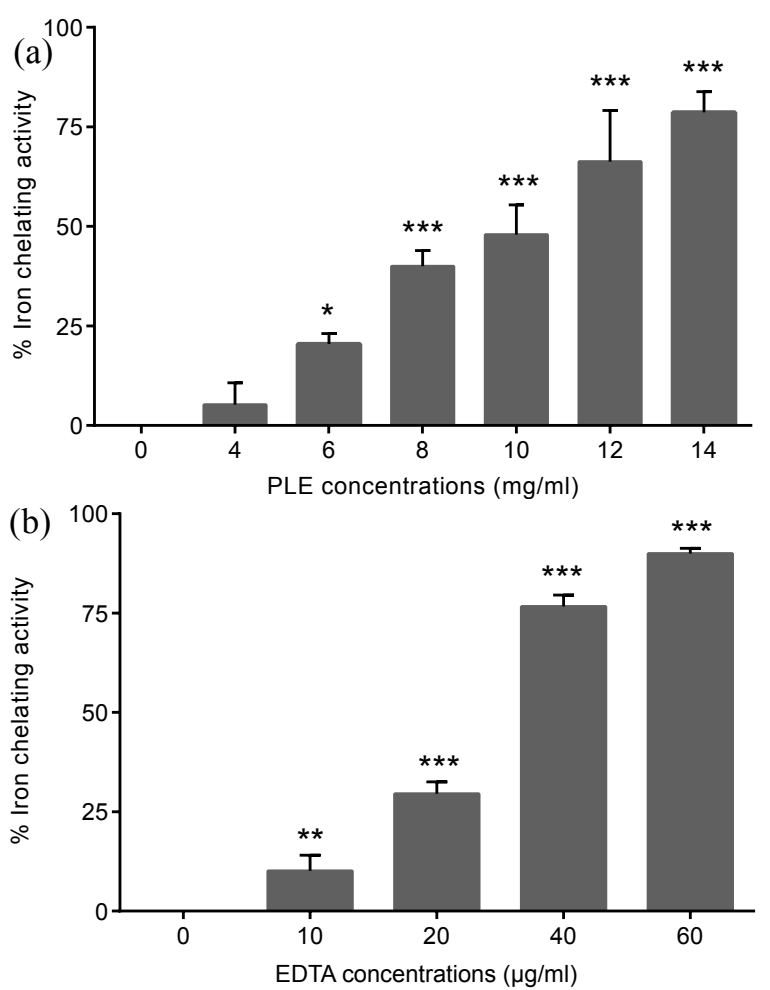

Fig. 4 Iron-chelating activity of (a) PLE and (b) EDTA. Data are represented as mean $\pm \mathrm{SD}, n=3$ each in triplicate, ${ }^{*} p<0.05, * * p<0.01, * * * p<0.001$.

\section{Effect of PLE on inhibition of ROS in PBMC}

The effect of PLE on intracellular ROS scavenging activity in PBMC was determined by DCFH-DA fluorochrome. The results presented in Fig. 5 indicated

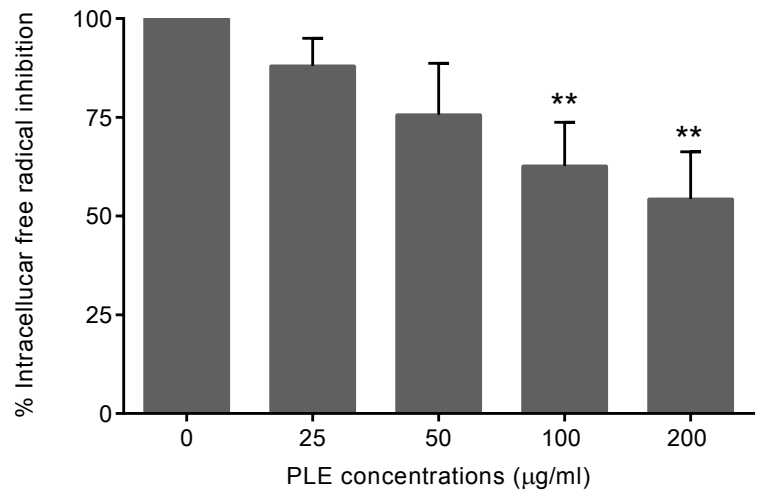

Fig. 5 Inhibitory effect of PLE on ROS production in PBMC. All data are expressed as mean $\pm \operatorname{SD}(n=3)$, ** $p<0.01$.

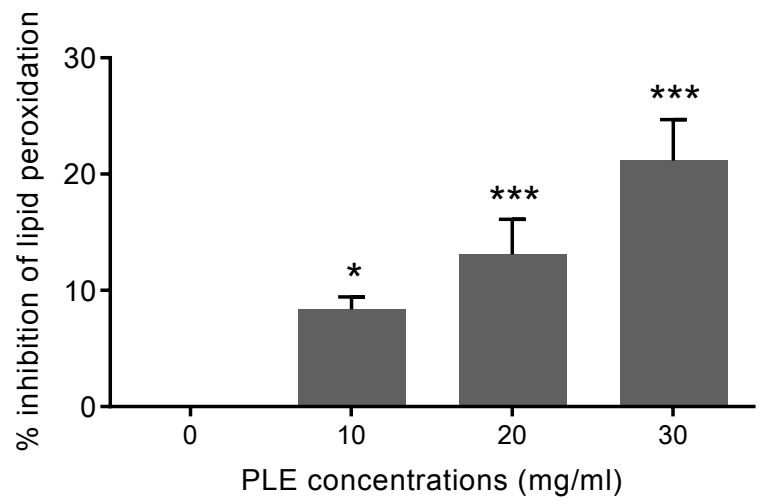

Fig. 6 Inhibitory effects of PLE on membrane lipid peroxidation. All data are expressed as mean $\pm \operatorname{SD}(n=3)$, * $p<0.05, * * * p<0.001$

that the concentrations of the PLE at $100 \mu \mathrm{g} / \mathrm{ml}$ and $200 \mu \mathrm{g} / \mathrm{ml}$ significantly inhibited intracellular ROS to $37 \%$ and $45 \%$, respectively.

\section{Effect of PLE on inhibition lipid peroxidation}

The results demonstrated that lipid peroxidation generated by haemoglobin induction was inhibited by PLE in a dose-dependent manner (Fig. 6). At a concentration of $30 \mathrm{mg} / \mathrm{ml}$ of PLE, the inhibition was approximately $27 \%$ when compared with the untreated sample.

The effect of PLE on RBC haemolysis induced by AAPH

In this study, PLE was used to examine the inhibition of in vitro haemolysis in human RBC induced by AAPH. The concentrations of PLE at 25, 50, 100, and $200 \mu \mathrm{g} / \mathrm{ml}$ could inhibit haemolysis by $4 \%$, $8 \%, 13 \%$, and $27 \%$, respectively (Fig. 7). These 


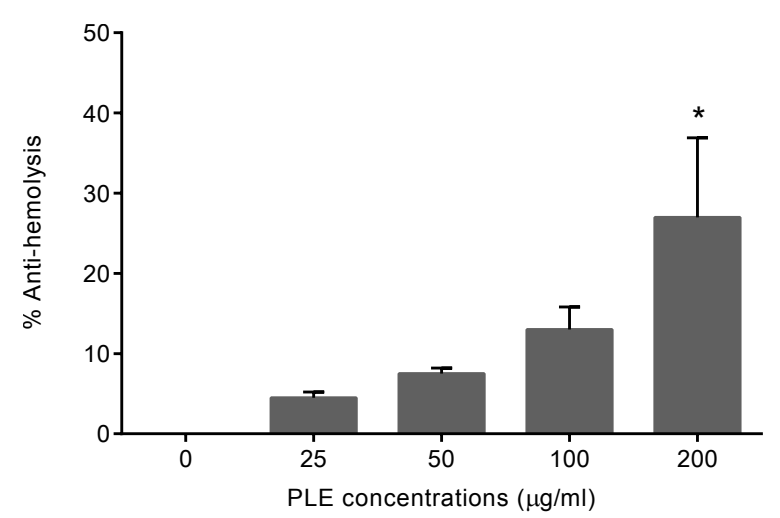

Fig. 7 Anti-haemolytic activity of PLE. All data are expressed as mean \pm SD $(n=3)$, * $p<0.05$.

results demonstrated the protective effect of PLE at $200 \mu \mathrm{g} / \mathrm{ml}$ significantly suppressed the oxidative damage of RBC membrane.

\section{DISCUSSION}

This study has demonstrated the protective effect of the polyphenol-rich perilla extract against oxidative stress and haemolysis. Perilla is a widely used medicinal plant and is grown in South-east Asian countries. It has been applied for the treatment of human diseases including asthma, colds, and allergies ${ }^{25}$. Rosmarinic acid is the main phenolic and phytochemical compound in PLE. In addition, apigenin, luteolin, caffeic acid, and glucoside derivatives have also been reported ${ }^{9}$. The data in this study indicated that the highest peak of rosmarinic acid was in the HPLC profile of PLE, with a lesser presence of apigenin and luteolin, inter alia. Phenolics and flavonoids have been thoroughly studied in relation to their antioxidation, iron chelation and lipid-peroxidation capacities. In line with the findings of previous studies, the antioxidant capacity of PLE was primarily attributable to the presence of several phenolic components ${ }^{9,26}$.

An imbalance between increased free radical production and deficient intracellular antioxidant systems naturally leads to oxidative stress ${ }^{27}$. Many pathological diseases such as atherosclerosis and other vascular diseases are caused by free radical driven oxidative processes. Red cell membrane polyunsaturated fatty acids (PUFA) including linoleic acid, linolenic acid and arachidonic acid could then be directly oxidized by ROS and consequently induced lipid peroxidation ${ }^{28}$. More than $80 \%$ of the cell membrane phospholipids are structurally composed of PUFA which have impor- tant biological functions such as receptor binding, transduction signalling, nerve transmission and eicosanoid biosynthesis ${ }^{29}$. The specific structures and functions of the membrane lipid bilayer of cells, mitochondria, and nucleus could be deformed and damaged by ROS, leading to pathological conditions and diseases such as dementia, schizophrenia, and ageing ${ }^{30}$. Membrane lipid peroxidation could be induced by met-haemoglobin containing oxidizing form and ferric ions ${ }^{31}$. In this study, a model of membrane lipids was produced by using linoleic acid emulsion. It was demonstrated that PLE could inhibit the formation of lipid peroxidation in the membrane model. This inhibition may be due to an iron-chelating property of PLE which interfered with the chain initiation reaction ${ }^{32}$.

In this study, we also validated that PLE clearly possessed an iron-chelating property by interfering with the $\mathrm{Fe}^{2+}$-ferrozine complex. PLE showed moderate activity in chelating of ferrous ions when compared with EDTA and strong Fe-NTA binding activity. These data confirmed the potent activity of PLE in iron binding, which might be able to prevent the formation of hydroxyl radicals from reactive iron via the Fenton reaction ${ }^{33}$. This protective action could be very useful in iron-overload status leading to several complications ${ }^{34}$. The ROS inhibition was analysed by the DCFH-DA method. $\mathrm{FeSO}_{4}$ were used as a source of hydroxyl radical generation in PBMC cells $^{35}$. In our laboratory, PLE significantly inhibited ROS formation in a dose-dependent manner. This result exhibited the capacity of PLE in ROS inhibition by scavenging the free radicals induced by ferrous ions ${ }^{36}$. Furthermore, PLE clearly exhibited anti-haemolytic activity by scavenging AAPHderived free radicals. This suggested that PLE decreased lipid peroxidation in RBC membrane, resulting in haemolytic protection. In addition, polyphenol-rich PLE revealed rosmarinic acid, apigenin and luteolin as the major polyphenol compounds that could be associated with the protective effect of RBC against free radical induced haemolysis. Thymus, another genus of the Lamiaceae, which also contains polyphenols and flavonoids mainly rosmarinic acid, could protect $\mathrm{RBC}$ haemolysis induced by AAPH ${ }^{37}$. We summarized that PLE played a vital role in free radical scavenging and ironchelating activities and subsequently prevented lipid peroxidation resulting in RBC haemolysis due to oxidative stress. In vivo studies of PLE are required and should be undertaken. Perilla products may be developed as health supplements which could be used in prophylaxis and treatment of NCDs. 
Acknowledgements: This work is kindly supported by a 2016 Research Grant of University of Phayao and the Plant Genetic under the Royal Initiative of Her Royal Highness Princess Maha Chakri Sirindhorn. We are grateful to Prof. Maitree Suttajit for his critical reading of the manuscript.

\section{REFERENCES}

1. Camps J, García-Heredia A (2014) Introduction: oxidation and inflammation, a molecular link between non-communicable diseases. Adv Exp Med Biol 824, $1-4$.

2. Pham-Huy LA, He H, Pham-Huy C (2008) Free radicals, antioxidants in disease and health. Int $J$ Biomed Sci 4, 89-96.

3. Brewer MS (2011) Natural antioxidants: sources, compounds, mechanisms of action, and potential applications. Compr Rev Food Sci Food Saf 10, 221-47.

4. Huyut Z, Beydemir S, Gülçin I (2017) Antioxidant and antiradical properties of selected flavonoids and phenolic compounds. Biochem Res Int 2017, 7616791.

5. He YK, Yao YY, Chang YN (2015) Characterization of anthocyanins in Perilla frutescens var. acuta extract by advanced UPLC-ESI-IT-TOF-MS ${ }^{n}$ method and their anticancer bioactivity. Molecules 20, 9155-69.

6. Diao Y, Miao Y, Lin X, Liao C, Guo F, Hu Z (2009) Comparative analysis of five varieties in Perilla frutescens (L.) Britton by 45S rDNA FISH and 5S rDNA sequences. Russ J Genet 45, 440-4.

7. Asif M (2011) Health effects of omega-3,6,9 fatty acids: Perilla frutescens is a good example of plant oils. Orient Pharm Exp Med 11, 51-9.

8. Lee JH, Park KH, Lee MH, Kim HT, Seo WD, Kim JY, Baek IY, et al (2013) Identification, characterisation, and quantification of phenolic compounds in the antioxidant activity-containing fraction from the seeds of Korean perilla (Perilla frutescens) cultivars. Food Chem 136, 843-52.

9. Khanaree C, Pintha K, Tantipaiboonwong P, Suttajit M, Chewonarin T (2018) The effect of Perilla frutescens leaf on 1,2-dimethylhydrazine-induced initiation of colon carcinogenesis in rats. J Food Biochem 42, e12493.

10. Meng L, Lozano YF, Gaydou EM, Li B (2008) Antioxidant activities of polyphenols extracted from Perilla frutescens varieties. Molecules 14, 133-40.

11. Natsume M, Muto Y, Fukuda K, Tokunaga T, Osakabe N (2006) Determination of rosmarinic acid and luteolin in Perilla frutescens Britton (Labiatae). J Sci Food Agr 86, 897-901.

12. Hong E, Kim GH (2010) Comparison of extraction conditions for phenolic, flavonoid content and determination of rosmarinic acid from Perilla frutescens var. acuta. Int J Food Sci Tech 45, 1353-9.

13. Jun HI, Kim BT, Song GS, Kim YS (2014) Structural characterization of phenolic antioxidants from purple perilla (Perilla frutescens var. acuta) leaves. Food Chem 148, 367-72.

14. Zhu F, Asada T, Sato A, Koi Y, Nishiwaki H, Tamura $\mathrm{H}$ (2014) Rosmarinic acid extract for antioxidant, antiallergic, and $\alpha$-glucosidase inhibitory activities, isolated by supramolecular technique and solvent extraction from Perilla leaves. J Agr Food Chem 62, 885-92.

15. Tantipaiboonwong P, Pintha K, Chaiwangyen W, Chewonarin T, Pangjit K, Chumphukam O, Kangwan N, Suttajit M (2017) Anti-hyperglycaemic and anti-hyperlipidaemic effects of black and red rice in streptozotocin-induced diabetic rats. Sci Asia 43, 281-8.

16. Pintha K, Yodkeeree S, Pitchakarn P, Limtrakul P (2014) Anti-invasive activity against cancer cells of phytochemicals in red jasmine rice (Oryza sativa L.). Asian Pac $J$ Canc Prev 15, 4601-7.

17. Kangwan N, Pintha K, Preedapirom W, Tantipaiboonwong P, Chumphukam O, Suttajit M (2015) Learning and memory enhancing effects of anthocyanin in black rice extract on cerebral ischaemia in mice. Sci Asia 41, 315-21.

18. Budluang P, Pitchakarn P, Ting P, Temviriyanukul P, Wongnoppawich A, Imsumran A (2017) Anti-inflammatory and anti-insulin resistance activities of aqueous extract from Anoectochilus burmannicus. Food Sci Nutr 5, 486-96.

19. Pangjit K, Udomsuk L, Upanan S, Pongjanta A, Chansiw N, Srichairatanakool S (2016) Iron-chelating and anti-hemolytic properties of ethanolic extract of lotus (Nelumbonucifera Gaertn) Leaves. J Med Assoc Thai 99(s1), 58-66.

20. Zhan Y, Dong CH, Yao YJ (2006) Antioxidant activities of aqueous extract from cultivated fruit-bodies of Cordyceps militaris (L.) link in vitro. $J$ Integr Plant Biol 48, 1365-70.

21. Pongjanta A, Pangjit K, Srichairatanakool S (2016) Antioxidant activity and cytotoxic effect of Ventilago denticulata Willd leaves extracts. $J$ Med Assoc Thai 99(s1), 51-7.

22. Sarkar M, Varshney R, Chopra M, Sekhri T, Adhikari JS, Dwarakanath BS (2006) Flow-cytometric analysis of reactive oxygen species in peripheral blood mononuclear cells of patients with thyroid dysfunction. Cytometry B 70, 20-3.

23. Kuo JM, Yeh DB, Pan BS (1999) Rapid photometric assay evaluating antioxidative activity in edible plant material. J Agr Food Chem 47, 3206-9.

24. Dai F, Miao Q, Zhou B, Yang L, Liu ZL (2006) Protective effects of flavonols and their glycosides against free radical-induced oxidative hemolysis of red blood cells. Life Sci 78, 2488-93.

25. Kamei R, Fujimura T, Matsuda M, Kakihara K, Hirakawa N, Baba K, Ono K, et al (2017) A flavanone derivative from the Asian medicinal herb (Perilla 
frutescens) potently suppresses IgE-mediated immediate hypersensitivity reactions. Biochem Biophys Res Comm 483, 674-9.

26. Yu H, Qiu JF, Ma LJ, Hu YJ, Li P, Wan JB (2017) Phytochemical and phytopharmacological review of Perilla frutescens L. (Labiatae), a traditional ediblemedicinal herb in China. Food Chem Toxicol 108, 375-91.

27. Lobo V, Patil A, Phatak A, Chandra N (2010) Free radicals, antioxidants and functional foods: Impact on human health. Pharmacogn Rev 4, 118-26.

28. Maurya PK, Kumar P, Chandra P (2015) Biomarkers of oxidative stress in erythrocytes as a function of human age. World J Meth 5, 216-22.

29. Bazinet RP, Layé S (2014) Polyunsaturated fatty acids and their metabolites in brain function and disease. Nat Rev Neurosci 15, 771-85.

30. Di Meo S, Reed TT, Venditti P, Victor VM (2016) Role of ROS and RNS sources in physiological and pathological conditions. Oxid Med Cell Longev 2016, 1245049.

31. Baron CP, Andersen HJ (2002) Myoglobin-induced lipid oxidation. A review. J Agr Food Chem 50, 3887-97.

32. Tang L, Zhang Y, Qian Z, Shen X (2000) The mechanism of $\mathrm{Fe}^{2+}$-initiated lipid peroxidation in liposomes: the dual function of ferrous ions, the roles of the pre-existing lipid peroxides and the lipid peroxyl radical. Biochem $J$ 352, 27-36.

33. Lin ES, Li CC, Chou HJ (2014) Evaluation of the antioxidant and antiradical activities of perilla seed, leaf and stalk extracts. $J$ Med Plant Res 8, 109-15.

34. Atilla E, Toprak SK, Demirer T (2017) Current review of iron overload and related complications in hematopoietic stem cell transplantation. Turk $J$ Hematol 34, 1-9.

35. Shao ZH, Vanden Hoek TL, Li CQ, Schumacker PT, Becker LB, Chan KC, Qin Y, et al (2004) Synergistic effect of Scutellaria baicalensis and grape seed proanthocyanidins on scavenging reactive oxygen species in vitro. Am J Chin Med 32, 89-95.

36. Wu TT, Hwang BR, Cho EJ (2011) Scavenging effect of extract from Perilla frutescens and rosmarinic acid from free radical and lipid peroxidation. Prev Nutr Food Sci 16, 224-9.

37. Khouya T, Ramchoun M, Hmidani A, Amrani S, Harnafi H, Benlyas M, Zegzouti YF, Alem C (2015) Antiinflammatory, anticoagulant and antioxidant effects of aqueous extracts from Moroccan thyme varieties. Asian Pac J Trop Biomed 5, 636-44. 